\title{
FARABEUF: LA ESCRITURA DEL FRAGMENTO
}

\author{
Armando Pereira*
}

Desde que el lector toma en sus manos la novela de Salvador Elizondo, mucho antes de abrir sus páginas y entregarse a la lectura, hay algo que le salta a la vista y se apodera un momento de su atención: es el título: Farabeuf o la crónica de un instante. En particular el subtítulo. O, para ser más específico, la imposibilidad que revela el subtítulo. ¿Cómo hacer la crónica de un instante, si la crónica es un relato a través del tiempo, y el instante, por definición, es la ausencia de tiempo? (El instante es al tiempo lo que el punto al espacio, diría Bergson. ${ }^{1}$ ) Y es precisamente a esa contradicción en los términos, a esa imposibilidad aparentemente insalvable, a la que habrá de enfrentarse la escritura de esta novela.

Para lograr ese objetivo, a todas luces irrealizable, la escritura echa mano de una serie de recursos narrativos que, en conjunto, terminan configurando un discurso ríspido, siempre tenso, dirigido más a la inteligencia que a la sensibilidad del lector y en el que, sobre todo, las coordenadas espacio-temporales acaban reducidas precisamente a ese punto y a ese instante de los que hablábamos hace un momento como la imposibilidad de toda escritura, precisamente porque, hasta el nouveau roman al menos, la escritura de la novela fue, ante todo, el desenvol-

* Departamento Académico de Estudios Generales, ITAM.

${ }^{1}$ Cfr. Henri Bergson, El pensamiento y lo moviente, 1972, Buenos Aires, La Pleyade. 
ARMANDO PEREIRA

vimiento de una historia en el espacio y en el tiempo. Sin duda, en Farabeuf se reúnen muchas de las técnicas empleadas por RobbeGrillet y Nathalie Sarraute en sus novelas, pero me parece que la escritura de Elizondo va más allá de cualquier encasillamiento estético o ideológico a que el lector se pueda sentir por momentos tentado. A algunas de esas técnicas habré de referirme aquí, no sólo para mostrar cómo una escritura puede rebasar su propia imposibilidad, sino sobre todo para evidenciar cómo una escritura logra encarnar, no como imagen sino como escritura misma, la propia escena que la convocó y de la que quiere dar cuenta.

Si ya el subtítulo del libro genera una cierta incertidumbre en el lector, por lo menos la sensación de que el autor se enfrenta a un reto del que difícilmente podrá salir bien librado, el discurso que desencadena la historia, ya desde las primeras páginas, no hace sino prolongar y profundizar el desconcierto inicial, previo a la lectura. El juego de remisiones pronominales con que inicia el texto, en un primer momento al menos, nos coloca ante la inseguridad (que es también ansiedad) de su referente. Sólo poco después, a medida que la narración avanza, nos damos cuenta que ese 'yo', 'tú', 'él', 'ella', 'nosotros', que son al mismo tiempo sujetos y objetos directos en cada sentencia, sólo están allí para referirse, de maneras diversas, en un juego de máscaras que los espejos multiplican, a esa única pareja que recorre al texto, a esa pareja original en torno a la cual se estructura la historia: el doctor Farabeuf y la Enfermera. Y sus dobles.

La presencia de los espejos en la novela tiene un sentido múltiple: no sólo duplica el espacio o la escena de que se trata, sino sobre todo está ahí, en el texto, como un mudo testigo de esa vacilación de la identidad, de esa persistente confusión del yo que hace que los personajes, a través de los distintos pronombres que los designan, sean siempre ellos mismos y al mismo tiempo otros: "Creyó ser nada más la imagen figurada en el espejo y entonces bajó la vista tratando de olvidarlo todo.”

${ }^{2}$ Salvador Elizondo, Farabeuf o la crónica de un instante, 1965, México, Joaquín Mortiz, p. 19. 
Pero sin duda lo más significativo de este juego especular es que la propia escritura se vuelve espejo de sí misma, un espejo obsesivo: un mismo motivo, que en muchos casos funciona más bien como leit motive del relato, se repite una y otra vez desde perspectivas (o espejos) distintas, agregando así, de una a otra, algo, quizá sólo una sombra o un gesto, que no estaba en la imagen primera. Así, por momentos, la lectura de la novela se asemeja a la lectura de una partitura musical para dos instrumentos, una sonata por ejemplo, en la que los motivos que la constituyen -el ruido de la tabla de la Ouija, los pasos del doctor Farabeuf en la escalera, el signo que traza un dedo sobre un cristal empañado, el tintineo de las monedas sobre la mesa, el reflejo inseguro de un cuerpo en el espejo, el golpeteo obsesivo de una mosca sobre el cristal de la ventana, un castillo de arena deshaciéndose en las olas, una estrella de mar- aparecen y desaparecen incesantemente, por un instante parecen diluirse en un motivo mayor, pero ese motivo enseguida adelgaza hasta volver a ellos con más fuerza, con más plenitud, y siempre cediendo su configuración de un instrumento al otro, configurando ese diálogo de voces complementarias que es toda la novela.

Ese juego de imágenes en el espejo nos remite necesariamente a otro elemento central en la escritura de Farabeuf: la memoria. La novela inicia y concluye con una pregunta: ‘¿Recuerdas?' Una pregunta que, además, se repite incesantemente a lo largo del texto. Y es que tanto Farabeuf como la Enfermera no han hecho otra cosa a lo largo del relato que intentar recordar una escena, la escena que los constituye como sujetos de deseo. Sólo que, en este caso, no se trata de esa memoria proustina que recupera su historia a través de un continuum. En este caso se trata, más bien, de una memoria que opera como una suerte de mecanismo fotográfico, pues lo que esa memoria busca es tan sólo perpetuar un instante. "La fotografía -dice en algún momento Farabeuf- es una forma estática de la inmortalidad."3 Precisamente inmortalizar ese instante en el que el deseo de los dos ha quedado fijado, y que no es otro que el deseo que brota en ellos al contemplar

${ }^{3}$ Ibid., p. 26. 
ARMANDO PEREIRA

la fotografía de un supliciado en el momento más álgido de su éxtasis. “Aspiras a un éxtasis semejante y quisieras verte desnuda, atada a una estaca. Quisieras sentir el filo de esas cuchillas, la punta de esas afiladísimas astillas de bambú, penetrando lentamente en tu carne. Quisieras sentir en tus muslos el deslizamiento tibio de esos riachuelos de sangre, ¿verdad?”4 Atrapados en esa imagen perversa, en la que ha quedado fijado su deseo, la repiten una y otra vez, como en un espejo, mediante el recuerdo. De ahí la indisoluble relación que se establece en el texto entre la fotografía como 'una forma estática de la inmortalidad' y la escritura como 'la crónica de un instante'.

Esa tortura china, llamada Leng Tch'e, a que se somete al magnicida, no consiste ni mucho menos en el acto burdo de despedazar un cuerpo. Se trata, más bien, de un procedimiento minucioso, de un método “de amputación por descoyuntamiento de los miembros en las articulaciones"5 que busca dosificar el dolor y prolongar la agonía de la muerte. Es sobre todo un procedimiento aséptico, que sabe en qué momento y en qué lugar producir la incisión, hacer el corte, como el procedimiento quirúrgico del Dr. Farabeuf consignado en el Précis de Manuel Opératoire de su autoría, como el procedimiento fotográfico, como el propio procedimiento de la prosa de Elizondo. Unos remiten a otros incesantemente haciendo de la escritura de esta novela un reflejo de esas prácticas: "el suplicio -escribe Elizondo- es una forma de escritura". ${ }^{6}$

Si la fotografía, en el momento de ajustar el enfoque y apretar el obturador, no hace sino producir un corte -el corte deseado- en ese continuum de realidad, como lo había hecho el Dr. Farabeuf con los cadáveres que disecciona o el torturador con el cuerpo del supliciado, la escritura de esta novela no es sino una manera también de torturar el cuerpo textual, de producir cortes e incisiones en el continuum del texto con la misma precisión y minuciosidad de quien disecciona un cadáver. En la novela de Elizondo no hay una continuidad de discurso,

${ }^{4}$ Ibid., p. 35.

${ }^{5}$ Ibid., p. 139.

${ }^{6}$ Ibid., p. 123. 
el corte es tan importante como el texto mismo y los fragmentos que resultan de esa ardua operación quirúrgica están ahí yuxtapuestos, intercambiables, como piezas de un imprevisible rompecabezas, sin continuidad en el tiempo, contemplándose unos a otros como espejos enfrentados, repitiendo obsesivamente una misma escena al infinito: precisamente la escena del deseo.

Roland Barthes, en un texto tan breve como substancioso, ha establecido la diferencia entre un 'texto de placer' y un 'texto de gozo': mientras que el primero (Flaubert, Proust, Stendhal) se desenvuelve en el interior de una cultura y establece una continuidad con ella, el segundo (Robbe-Grillet, Sollers, Duras) se escinde de esa cultura y se le enfrenta 'bajo la forma de un escándalo'; 7 si el primero desarrolla su historia en la continuidad temporal hasta alcanzar un clímax y un desenlace que podríamos calificar de orgásmico, el segundo subvierte esa continuidad fragmentándola y haciendo de cada fragmento la negación de todo climax y de todo desenlace: el deseo no quiere satisfacerse; quiere perpetuarse como tal.

Es precisamente a ese texto de goce al que nos enfrentamos en la lectura de Farabeuf. Si la novela de Elizondo se apoya en una cultura es tan sólo para decir lo que esa cultura oculta; lo que esa cultura, al afirmar su continuidad, esconde detrás de la letra. "Lo que hay que reconocer -ha escrito Lacan- es que el goce como tal está interdicto a quien habla, o más aún que no puede ser dicho sino entre líneas.” Producir un corte en la continuidad de un discurso (de un cuerpo, de una gama de realidad) es obligar a leer entre líneas, a leer justamente lo que esa continuidad oblitera. Y lo que aparece allí no es más que una escena sin continuidad en la historia: la de un cuerpo fragmentado (como el propio cuerpo de la escritura) del que brota un deseo impronunciable; impronunciable precisamente porque no apela al sujeto (al discurso), sino a esa ausencia de sujeto (de discurso) que es el cuerpo fragmentado.

${ }^{7}$ Roland Barthes, El placer del texto, 1974, Buenos Aires, Siglo XXI, p. 30.

${ }^{8}$ Citado en Roland Barthes, op. cit., p. 31. 
ARMANDO PEREIRA

Edipo, el sujeto por excelencia, reconoce el lugar de cada uno en la historia familiar. Ahí están Papá (el nombre de la ley) y Mamá (el objeto del deseo) e inmediatamente teje una historia entre los tres. Pero un deseo que se ubica antes de la ley (antes del sujeto) no apela a un cuerpo completo, sino a sus fragmentos: un pie, un seno, el ombligo, una par de nalgas, eso que Lacan ha llamado 'objetos parciales', 9 y a partir de los cuales Deleuze y Guattari han generado sus 'máquinas deseantes', ${ }^{10}$ cuyas conexiones se producen en el olvido de toda ley. Fragmentar un cuerpo o una historia es negar la totalidad como sentido, es cuestionar incluso la propia noción de sentido.

Si se puede hablar, entonces, de Farabeuf como una escritura de deseo, es porque se ubica antes (después o al margen) de toda ley. La ley opera sólo allí donde hay un sujeto que la reconoce y en la que la ley se reconoce; allí donde hay un discurso que la despliega en su propia ilación discursiva. El corte, la incisión, la fisura, la fragmentación -prácticas preedípicas y modus operandi de la escritura de Farabeuf- no son tanto una transgresión, que implicaría el reconocimiento de la ley, sino su desconocimiento. La certeza, más bien, de que la escritura no siempre obedece a normas de género preestablecidas, que se puede escribir también desde otra parte.

${ }^{9}$ Jaques Lacan, Escritos 1, 1971, México, Siglo XXI.

${ }^{10}$ Gilles Deleuze y Félix Guattari, El anti-edipo. Capitalismo y esquizofrenia, 1985, Barcelona, Paidós. 